УДК 130.14

https://orcid.org/0000-0002-5624-2928

\title{
ВОЗМОЖНО ЛИ ГОВОРИТЬ О РАЦИОНАЛЬНОСТИ ЙОГИ?
}

\author{
В.В. Лобас, аспірантка Національного технічного університету "Харківський \\ політехнічний інститут"
}

У світовій філософській практиці йоги приділяють величезну увагу: читаються курси в провідних університетах світу, відкриті різного роду проекти по вивченню иього виду духовної техніки, тривають дослідження в області історії, $i$ звичайно є ряд вчених, які пов'язують знання про неї, як з науковим характером досліджень, так й з практичним іï застосуванням у сучасній культурі. На жаль, у вітчизняній літературі недостатньо уваги приділяється такій давній та актуальній в сучасному світі філософії. У статті ми ставимо завдання проаналізувати иеей бік багатогранного людського життя з позицій сучасного європейського дослідника. Східну культуру можна розглядати в контексті мистецтва, релігії, міфологї, але виникає питання: а чи можна ї̈ розглядати й оцінювати в контексті розумового, раціонального дискурсу?

На основі стародавніх текстів, на основі робіт відомих індологів, сучасних європейських філософів зроблена спроба описати ращіональність йоги $i$ дати їй визначення. Автор виходить на загальний характер раџіональності Сходу, представлений космологічні-міфологічним світоглядом. Робить висновок, щзо для людини Сходу існують інші норми і критерії раціональності, ніж для європейськи орієнтованого світогляду. Автор також аналізує характер оформлення мислення людини з такою формою світогляду.

Актуальность. Сегодня мы наблюдаем огромнейший интерес к культуре, жизни, философии Востока. Философия йоги занимает в этом ряду одну из первых позиций. Это связано со многими факторами. О йоге написано достаточно много литературы, но ее глубокий и всесторонний анализ в нашей отечественной философии до сих пор отсутствует. Нам бы хотелось подчеркнуть, что в мировой философской практике йоге уделяют огромное внимание: читаются курсы в ведущих университетах мира, открыты различного рода проекты по изучению этого вида духовной техники, продолжаются исследования в области истории и конечно есть ряд ученых, которые связывают знания о ней, как с научным характером исследований, так и с практическим ее приложением в современной культуре [1].

В статье мы ставим задачу проанализировать эту сторону многогранной человеческой жизни с позиций современного европейского исследователя. 
Восточную культуру можно рассматривать в контексте искусства, религии, мифологии, но возникает вопрос: а можно ли ее рассматривать и оценивать в контексте мыслительного, рационального дискурса?

Новизна. Предпринята попытка описать рациональность йоги и дать ей определение.

Основная часть. Можно, конечно, говорить о природе мышления как психофизиологической, физиологической, генетической, биофизической или о логике как опыте описания мышления, но ни то, ни другое - не мышление. Мысль, мышление как идея, в любой философии, выросшей из Просвещения всегда антропологична, субъектна и объектна. Прекрасный анализ и описание рациональности мы находит в работе Дольськой O.A. «Трансформации рациональности в поле образования». Мы будем опираться на идеи, изложенные в ней, поскольку в первой главе дается концептуализация рациональности с возможными вариантами ее понимания и анализом огромной литературы, посвященной проблеме рациональности [2]. Поэтому мы будем опираться в нашем исследовании на следующее понимание рациональности: «рациональность как руководство к действию, оформленное мыслительными процедурами» [2].

Несмотря на утверждение Г.Г. Гегеля об отсутствии рациональности восточного характера, огромный интерес именно с конца XIX в к мышлению, к рациональности Востока разбил это утверждение. Йога известна из древних текстов Бхагавад Гиты. Однако активное знакомство европейцев и американцев с ней началось только лишь с XIX века. Широкое распространение философия йоги достигла благодаря Свами Вивеканаде, который в 1893 году вынес на обсуждение широкой общественности эту тему. На огромном форуме под названием «Parliament of the World's Religions», где присутствовало колоссальное количество слушателей, он представил эту индийскую технику жизни и мышления, учение, философию и дал старт проекту йога в современном мире. Таким образом, он положил начало современной йоге, которая представила в систематической форме 
широчайший диапазон различных йогических и духовных практик. И хотя разновидности йоги Кришна упоминает в Бхагавад Гите, будучи наставником Арджуне, более широкое распространение они получили именно благодаря деятельности Свами Вивеканады [3].

Гиридхар Йогишвар, известный современный культуролог и религиовед, так написал о нем: «Его заметки по Радже Йоге, Карма Йоге, Бхакти Йоге и Джнане Йоге - постоянно свежие источники родниковой воды, которые поливают любознательные духовные умы настоящего и будущего времени» [4]. Он же знакомит нас с четким различием четырех видов йоги. Его анализ отличается глубиной и, как ни странно, связан с современном понимаем этого удивительного вида культурно-философских техник. Поскольку мы поставили задачу рассмотреть йогу в контексте дискурса европейского мышления, а именно в контексте вопроса о возможности/невозможности говорить о рациональности йоги, нам бы хотелось привести высказывания этого мыслителя о видах и отличиях их между собой. «Йога - термин, представленный на санскрите, и четыре вида Йоги имеют на санскрите различные имена. Эти виды отличаются по тому, с Кем именно старается установить связи Человек, на что направлены силы Человека. Человек получает различный статус в зависимости от того, Кто выступает целевой стороной его жизни. В том виде, в котором Человек ищет союз с Абсолютом, получает статус Йога. Того, кто ищет союз, благодаря его действиям и работе, называют Карма Йогом. Того, кто ищет союз через мистику, называют Раджа Йогом. Тот, кто ищет его через любовь, получает статус и имя Бхакти Йогом. А кто стремится достигнуть союза через философию, называют Джнана Йогом» [4].

Современный независимый ученых Элизабет Де Михелис детально и тщательно описывает историю современной йоги и разъясняет вышеупомянутые четыре пути йоги. Анализ последних не обходится без упоминания Свами, и нам бы хотелось привести ее цитату: «Мы считаем, что универсальная религия Свами приспосабливаема ко всем обстоятельствам, 
потому что она угождает всем типам людей: она включает четыре различных типов «вероисповедания», адаптированного к «четырем общим типам человека... рационального, эмоционального, мистического и рабочего» [5, с. 124]. Также в нашем исследовании огромную роль мы отводим работам знаменитых индологов Ж. Демюзиля и М. Элиаде.

В попытке разобраться с объектом мышления йогина мы будем опираться на размышления о мышлении А. Пятигорского. Его цитата о понимании объекта мышления позволит нам разобраться в формировании мышления йогина. «Объектом может быть только сама мысль (citta), но мыслимая только как «возникающая» (utpanna), как одно со своим возникновением (utpada). Этот объект называется «возникновение мысли» (cittotpada), но, строго говоря, это просто «мысль как особый объект», поскольку она йогически представима только как возникновение. Что значит йогически? Это значит, что данный объект, обозначенный как «возникновение мысли», существует в процессе, где все созерцается как дхарма, то есть как мгновенная мысль. Этот процесс, или эта разновидность йоги, обычно называется dhyana, иногда bhavana [7].

Мысль возникает в трех сферах: сфера чувственного (kama), сфера формы (rupa) и сфера, где нет формы (arupa). Сфера - это образ места дхьянического созерцания, места, в котором уже измененное сознание направлено на конкретные йогические объекты (kasina). Так, первая из них это сфера действия всех шести органов чувств при преобладании осязания (контакта, соприкосновения) и одновременно при отсутствии дхьянического созерцания. Мир, как он есть (включая нормальную психику и нормальные состояния сознания), не может себя созерцать без предварительной трансформации себя в созерцаемый объект, поэтому «сфера» является одним из факторов такой трансформации. Тогда первая сфера, сфера чувственности, в которой в данном «случае» возникает мысль, является дхьяническим «образом места», где нет йоги или, по крайней мере, высших ступеней последней. Вторая сфера - сфера формы является местом, где созерцаемые 
объекты лишены некоторых чувственных характеристик психики, где объекты созерцаются как нечувственные формы сознанием, уже значительно йогически трансформированным на всех четырех ступенях (иногда их пять) дхьяны. И наконец, третья сфера, бесформенности, генерируется только четырьмя высшими состояниями йоги сосредоточения. Сознание здесь уже полностью трансформировано и объекты сосредоточения (samadhi) созерцаются как лишенные всех чувственных характеристик, так же, как и отсутствия этих характеристик. Здесь нет ни формы, ни не формы, ни протяженности, ни не протяженности, ни цвета, ни не цвета и т.д. Это предел йоги, так сказать, то место, за которым йога уже ничего не генерирует [7].

Из всего сказанного о «сфере» ясно видно, что она, с одной стороны, обозначает все, что созерцается в дхьяне и самадхи, а с другой - все, что созерцает, то есть уже трансформированное йогой сознание. Три сферы практически «покрывают» весь мир, как мир реально или потенциально трансформируемых в созерцании вещей и событий, устанавливая этим некоторую «область йоги», которая «космологически» соответствует вертикальному (иерархическому) расположению трех миров буддийской (да отчасти и древнеиндийской в целом) мифологии: миру плотских существ, миру богов и миру высших (трансцендентальных) богов. В этом смысле эта область представляется промежуточной между феноменальным миром и немиром нирваны. (Последнее - только весьма условно, ибо даже трансцендентальная йога не ведет к нирване, хотя и соответствует Телу Вкушения (sambhogakaya) Будды) [7].

Находясь в узких рамках статьи, мы остановимся на первой сфере (avacara), в которой возникает мысль, - важнейший элемент того, что можно было бы условно назвать космологией.

Чтобы познакомиться с космологией древних, нам бы хотелось рассмотреть такие традиционные феномены культуры, как индивидуальная душа, человек, космос, время, пространство, материя, соотношение Добра и Зла. Наша задача, выявить те принципы, которые легли в основу философии 
йоги. «Логическое пространство» (Л. Витгенштейн) формирования рациональности йоги мы будем исследовать в оригинальных источниках древней восточной мысли. Для этого нам необходимо ориентироваться на тексты Вед и Упанишад. Веды - это древние санскритские тексты, которые представляют собой застывшее мировоззрение арийцев, это священные тексты, не имеющие авторов. Упанишады являются критическим осмыслением ведийского мировоззрения. «Махабхарата» (и ее часть «Бхагавадгита») является влиятельным эпосом, который формирует мышление индийского человека. Интерес к рациональности не случаен. Дело в том, что человеческая мысль всегда пытается упорядочить и согласовать элементы мира и человеческого сознания. Такой двойной процесс позволяет выявить специфику культуры. На наш взгляд, способы и нормы упорядочивания и согласования репрезентируют собой рациональность, а от их характера зависит тип культуры.

Анализируя вышеназванные тексты, можно смело сказать, что древний мыслительный мир индийцев - мифологический, все свои размышления они производят в дискурсе космического. Жорж Демюзиль, французский исследователь индоевропейской мифологии, характеризовал их мышление как философское, и в то же время как абсолютистское, догматическое, моральное и мистическое [8].

Одна из характерных черт индийской религиозной мысли стала огромная роль, ее можно охарактеризовать как парадигмальную, единства противоположностей. Ярким подтверждением тому стал образ Агни жертвенный огонь, просвещение, интеллект. Агни описывается одновременно и через свои огненные проявления, и через свои божественные черты. Это также и образ «яростного змея». Змей-Огонь есть невидимая модальность того, что в видимой модальности есть Агни. То есть змей - это виртуальность огня, тогда как тьма есть непроявленный свет. Если его отождествляют с солнцем, то оно освобождается от ночи. Если отождествляют с Богом Сомой, то он освобождается от старой кожи, 
достигая бессмертия. Агни обладает высокими духовными качествами, наделен великим умом и ясновидением. Например, концепция божественной творческой игры (лила) выводится из «игры» языков пламени. Связь огня как света и разума выводится и подчеркивается постоянно.

Миф во всех книгах поливалентен: помимо космогонического значения, он наполнен также натуралистическими и историческими валентностями [9, с.192]. М. Элиаде считает, что в древние времена борьба между Индрой и Вритрой составляла мифо-ритуальный сценарий праздников Нового года, который обеспечивал возрождение мира [9, с. 192]. Миф также биокосмологичен. Опять же если взять образ Агни, то он выполнял одну из ведущих ролей в биокосмогонической теории индийской духовности В ведическую эпоху он отождествлялся с «огненной энергией, блеском, действенностью, великолепием, сверхъестественным могуществом» [9, с. 194]. Нам также хотелось бы отметить, что круг отождествлений привязан к идее сильного семени, к идее «внутреннего жара», к аскетическому рвению и практике йоги.

Для нас интересен также феномен формирования одного из ведущих принципов философии и практики йоги - принцип Сомы. В «Ригведе» этому Богу посвящена целая глава - девятая. Он ясновидец, умен, мудр, щедрый и победоносный, он друг Индры, его называют Царь Сома. Он присутствует в ритуальном событии отжимания сока из растения, где подчеркивается мистика космического и биологического, что свидетельствует о поливалентности мифа. Напиток этого растения способствовал введению в экстаз, приобщению к миру богов, формированию уверенности в «несмерти», что нашло отражение в многочисленных гимнах «Ригведы». Попытки найти подобные состояния вне приобщения к этому напитку, привело к поиску иных методов достижения подобного состояния: аскеза, медитации, техники йоги, мистическая самоотдача. И хотя роль бога Сомы была не огромной, но принцип, появлению которого он способствовал с его метафизикой космологического и жертвенного одновременно, лег в основу 
мифологическо-космологической рациональности йоги [9, с.196].

Основы философии санкхья-йоги можно найти в космогонии, описанной в знаменитом гимне «Ригведы», в котором поэт спрашивает себя, как Бытие могло выйти из Небытия (Ригведа гл.Х). В ней же рассказывается о первом семени Сознания. Здесь же присутствует идея о том, что Вселенная, как и сознание проистекают из творческого желания (камы), что в дальнейшем нашло свое продолжение в философии йоги.

Всем доступная йога изложена в «Бхагавадгите» (напоминаем, что это одна из больших частей «Махабхараты»), уже в ней мы узнаем о двух противоположных техниках йоги. В Гите изложена техника «йоги деяния», которая осуществляется как «отказ от плодов деяний». Подчеркивается ее оригинальность. Когда аскеты и йогины жертвуют своей психофизиологической деятельностью, они отказываются от этой деятельности и придают ей трансперсональное значение, жертвой стирая свои грехи. [10, с. 205]. Такая трансмутация мирских дел в ритуалы возможна через йогу. «Человек деяний» может спастись, то есть избежать последствий своего участия в жизни мира, а именно - отделить себя от своих дел и их последствий. Действовать необходимо отстраненно, не волнуясь и не ожидая результата, а это значит достичь самообладания и спокойствия, которые, следовательно, может сообщить одна лишь йога. Это так называемая «йога деяния».

Вторая техника йоги в Гите представлена и описана как техника созерцания «Йога выше, чем аскеза (тапас) и даже выше, чем знание, и выше, чем жертва». Но медитация йогина достигает конечной цели только в том случае, если он сосредоточен на Боге [10, с. 205]. Вторая техника является наивысшей точкой и триумфом занятий йогой. Это одновременно и возвышенный мистический культ, высший путь.

«Бхагавадгита» также рассматривает вопрос о роли Истории и ставит акцент на историчности человек, предлагая наиболее всеобъемлющее решение для человека. Если «перевести» такие зарисовки Востока на язык западной философской мысли, то проблема сводится к следующему: «как 
разрешить противоречивую ситуацию, порожденную тем, что человек, с одной стороны, находится во Времени, предназначен Истории, а, с другой стороны, знает, что будет «проклят», если позволит временности и историчности исчерпать себя, и, следовательно, должен любой ценой найти в этом мире путь, который ведет в трансисторический и вневременной план» $[10$, с. 206]. Это не могло не отразиться и на мировоззрении современного человека, что, вызывало интерес к йоге у человека Запада.

Особого значения приобретают такие феномены, как освобождение, разъединение и объединение. Согласно учению йоги, освобождение требовало отстранения от мира вплоть до отрицания человеческой жизни как способа существования в Истории (характерные для йоги тенденции и методы, разработанные для отделения духа от психоментального опыта свидетельствуют об этом). Открытие идеи всеобщего страдания, бесконечного цикла перерождений направило поиск спасения к определенной цели: освобождение как отказ от следования нуждам жизни, социальным нормам (кстати, идея неизбежности переселения душ сделала самоубийство бесполезным). А вот спасение через гнозис сравнивалось с «пробуждением», с «прозрением». Поэтому отделение от мира (место страданий, тюрьмы незнания), уединение и аскетические практики способствовали религиозному обесцениваю мира. Но зато обострялся дуализм Дух-Материя. В концепции санкхья-йоги, материя упорядочивается спонтанно и бессознательно, чтобы служит душе. Этот процесс характерен и для Природы, которую освещает Вишну-Кришна.

Огромная роль отводилась моральной причинности как обострению такого дуализма (Дух-Материя). Под ней понимали то, что Космос пронизан справедливостью, а каждый получает то, что заслуживает. На протяжении веков противопоставление Добра и Зла было одним из многих примеров космических, политических, религиозных диад, полярностей, с помощью которых обеспечивалось ритмическое существование мира.

Мир считался смесью духовного и материального и именно поэтому, 
намеченные в Упанишадах дуальности, приобретают резко выраженное в дуалистических онтологиях и методах разделения, разработанных в йоге. При правильном совершении ритуала верующий отделял свою небесную сущность от ее материального выражения. Освобождение - это результат длительного и напряженного стремления к отделению духа от материи, света от тьмы. Интересен тот факт, что архаические представления о заслуге или вине души нашли выражение в шести цветах тела: черный, темно-синий, серый характеризуют жителей ада, а желтый, розовый и белый - существ, живущих на земле. При этом чистый белый цвет характерен только для тех, кто поднимается к вершине Вселенной. Поэтому первая медитация человека на своей чистой сущности получает название «первой белой медитацией» $[10$, c. 195$]$.

Выводы: Для человека Востока существуют другие нормы и критерии рациональности, нежели для европейски ориентированного мировоззрения. Рациональность философии йоги должна стать основой для исследований практик и технологий йоги. Ей можно дать условное определение, но ее глубокий и уходящий корнями в седую древность смысл, требует тщательного и скрупулёзного анализа. Объединение всех аскетических практик и религиозных учений происходит в Гите, поэтому без анализа ее текстов, разобраться в рациональности йоги невозможно. Рациональность йоги носит мифологическо-космологический характер: это априорная схема умовосприятия человеком мира и себя самого, в которой представления о карме и нирване были главными в мироориентации и деятельности, а мистика космического и биологического подчеркивала поливалентность этих априоризмов. Такая рациональность позволяет йогину мысленно перемещаться из мира плотских существ в мир богов и в мир трансцендентальных богов. Последний мир представляется как промежуточный между феноменальным миром и не-миром нирваны.

Различные индийские практики, техники, методы, имеющие целью освободить дух через разъединение, приобретали своих последователей, 
потому что после «Упанишад» отказ от жизни, обусловленной социополитическими структурами и историей, стал самым достойным сотериологическим решением.

Отсюда ориентация йогина на внутреннее самосовершенствование и безразличие к внешнему миру. Моральная порядочность и космический порядок здесь являются понятиями одного уровня, начиная с нравственных позиций индивидуальной души, которая сродни духовной сущности Космоса, а Добро и Зло выступают метафорами ритмического характера жизни, как Космоса, так и Человека.

\section{Список використаних джерел}

1. Стерледев Р.К. Синергетика и процессы конвергенции западного и восточного. 2008. // Електрон. pecypc. [Режим доступу] https://cyberleninka.ru/article/n/sinergetika-i-protsessy-konvergentsii-zapadnogo-ivostochnogo-tipov-videniya-cheloveka

2. Дольская О.А. Трансформации рациональности в поле образования / О.А. Дольськая.: Монография. Харьков: НТУ «ХПИ», 2013. - 352 с.

3. Parliament of the World's Religions // Електрон. ресурс. [Режим доступу] https://parliamentofreligions.org/

4. Swami Vivekananda's concept of Jnana Yoga, Raja Yoga, Karma Yoga and Bhakti Yoga giridhar Yo. Ancient Science of Life, Vol. No. XIII Nos. 3 \& 4, January-April 1994, Pages 261-265 // Електрон. ресурс. [Режим доступу]

https://www.researchgate.net/publication/224897898 Swami_vivekananda's concept of jnana yoga raja yoga ka rma yoga and bhakti yoga

5. De Michelis Elizabeth. A History of Modern Yoga Patanjali and Western Esotericism. First published 2004 by Continuum / Elizabeth De Michelis // Електрон. pecypc. [Режим доступу] https://www.academia.edu/4019193/A_History_of_Modern_Yoga_Patanjali_and_Western_Esotericism

6. De Michelis E. A History of Modern Yoga: Patanjali and Western Esotericism / Е. De Michelis // Електрон. pecypc. [Режим доступу] https://modernyogaresearch.academia.edu/ElizabethDeMichelis

7. Пятигорский А. Пять лекций по Буддийской философии. Лекция третья / Мысль и сознание - знаем ли мы, о чем это? Возникновение мысли / А. Пятигорский // Електрон. ресурс. [Режим доступу] https://alexanderpiatigorsky.com/ru/teksty/knigi/filosofskie-i-buddologicheskie-knigi/pyat-lekcij-po-buddistskojfilosofii/lekciya-3/

8. Dumezil G. Mitra -Varuna. Uploaded by gulistan.alpaslan8134. Full description / Georges Dumezil.// Електрон. ресурс. [Режим доступу] https://de.scribd.com/document/330391972/Georges-Dumezil-Mitra-Varunapdf

9. Элиаде М. История веры и религиозных идей. В 3-х тт. - Т.1. От каменного века до эленсиских мистерий / М. Элиаде. - М. : Критерион, 2002. - 464 с.

10. Элиаде М. История веры и религиозных идей. В 3-х тт. - Т.2. От Гаутамы Будды до триумфа христианства / М. Элиаде. - М. : Критерион, 2002. - 512 с.

11. Веды /Упанишады // Електрон. ресурс. [Режим доступу]

https://www.dtv.de/_files_media/title_pdf/leseprobe-34379.pdf

12. Мхахабхарата // Електрон. ресурс. [Режим доступу]

http://agnigarh.tezu.ernet.in/ pra2014/Mahabharata\%20of\%20Vyasa.pdf

13. Ригведа // Електрон. ресурс. [Режим доступу] http://www.sanskritweb.net/rigveda/rigveda.pdf

References

1. Sterledev R.K. Synerhetyka y protsessы konverhentsyy zapadnoho y vostochnoho. 2008. // Elektron. resurs. [Rezhym dostupu] https://cyberleninka.ru/article/n/sinergetika-i-protsessy-konvergentsii-zapadnogo-i-vostochnogotipov-videniya-cheloveka

2. Dolskaia O.A. Transformatsyy ratsyonalnosty v pole obrazovanyia / O.A. Dolskaia.: Monohrafyia. - Kharkov: NTU «KhPY», 2013. - 352 s.

3. Parliament of the World's Religions // Elektron. resurs. [Rezhym dostupu] https://parliamentofreligions.org/ 
4. Swami Vivekanandas concept of Jnana Yoga, Raja Yoga, Karma Yoga and Bhakti Yoga giridhar Yo. Ancient Science of Life, Vol. No. XIII Nos. 3 \& 4, January-April 1994, Pages 261-265 // Elektron. resurs. [Rezhym dostupu] https://www.researchgate.net/publication/224897898_Swami_vivekanandas_concept_of_jnana_yoga_raja_yoga_kar ma_yoga_and_bhakti_yoga

5. De Michelis Elizabeth. A History of Modern Yoga Patanjali and Western Esotericism. First published 2004 by Continuum / Elizabeth De Michelis // Elektron. resurs. [Rezhym dostupu] https://www.academia.edu/4019193/A_History_of_Modern_Yoga_Patanjali_and_Western_Esotericism

6. De Michelis E. A History of Modern Yoga: Patanjali and Western Esotericism / E. De Michelis // Elektron. resurs. [Rezhym dostupu] https://modernyogaresearch.academia.edu/ElizabethDeMichelis

7. Piatyhorskyi A. Piat lektsyi po Buddyiskoi fylosofyy. Lektsyia tretia / Mыsl y soznanye - znaem ly mы, o chem эto? Voznyknovenye mыsly / A. Piatyhorskyi // Elektron. resurs. [Rezhym dostupu] https://alexanderpiatigorsky.com/ru/teksty/knigi/filosofskie-i-buddologicheskie-knigi/pyat-lekcij-po-buddistskoj-

filosofii/lekciya-3/

8. Dumezil G. Mitra -Varuna. Uploaded by gulistan.alpaslan8134. Full description / Georges Dumezil.// Elektron. resurs. [Rezhym dostupu] https://de.scribd.com/document/330391972/Georges-Dumezil-Mitra-Varuna-pdf

9. Эlyade M. Ystoryia verы y relyhyoznыkh ydei. V 3-kh tt. - T.1. Ot kamennoho veka do эlensyskykh mysteryi / M. Эlyade. - M. : Kryteryon, 2002. - 464 s.

10. Эlyade M. Ystoryia verы y relyhyoznыkh ydei. V 3-kh tt. - T.2. Ot Hautamы Buddы do tryumfa khrystyanstva / M. Эlyade. - M. : Kryteryon, 2002. - 512 s.

11. Vedы /Upanyshadы // Elektron. resurs. [Rezhym dostupu] https://www.dtv.de/_files_media/title_pdf/leseprobe34379.pdf

12. Mkhakhabkharata // Elektron. resurs. [Rezhym dostupu]

http://agnigarh.tezu.ernet.in/ pra2014/Mahabharata\%20of\%20Vyasa.pdf

13. Ryhveda// Elektron. resurs. [Rezhym dostupu] http://www.sanskritweb.net/rigveda/rigveda.pdf

\section{ВОЗМОЖНО ЛИ ГОВОРИТЬ О РАЦИОНАЛЬНОСТИ ЙОГИ?}

\section{Лобас В.В.}

В мировой философской практике йоге уделяют огромное внимание: читаются курсы в ведущих университетах мира, открыты различного рода проекты по изучению этого вида духовной техники, продолжаются исследования в области истории, и конечно есть ряд ученых, которые связывают знания о ней, как с научным характером исследований, так и с практическим ее приложением в современной культуре. К сожалению, в отечественной литературе недостаточно внимания уделяется такой древней и актуальной в современном мире философии. В статье мы ставим задачу проанализировать эту сторону многогранной человеческой жизни с позиций современного европейского исследователя. Восточную культуру можно рассматривать в контексте искусства, религии, мифологии, но возникает вопрос: а можно ли ее рассматривать и оценивать в контексте мыслительного, рационального дискурса?

На основе древних текстов, на основе работ известных индологов, современных европейских философов предпринята попытка описать рациональность йоги и дать ей определение. Автор выходит на общий характер рациональности Востока, представленный космологически-мифологическим мировоззрением. Делает вывод, что для человека Востока существуют другие нормы и критерии рациональности, нежели для европейски ориентированного мировоззрения. Автор также анализирует характер оформления мышления человека с такой формой мировоззрения.

\section{IS IT POSSIBLE TO SPEAK ABOUT RATIONALITY OF YOGA?}

\section{Viktoria Lobas}

In world philosophical practice, yoga is given great attention: courses are given at leading universities of the world, various kinds of projects are being opened to study this type of spiritual technique, research in history continues, and of course, there are a number of scientists who associate knowledge about it as a scientific character., and with its practical application in modern culture. Unfortunately, in domestic literature not enough attention paid to such an 
ancient and relevant philosophy in the modern world. In the article we set the task to analyze this aspect of multifaceted human life from the standpoint of the modern European researcher. Eastern culture can be viewed in the context of art, religion, mythology, but the question arises: can it be viewed and evaluated in the context of mental, rational discourse?

On the basis of ancient texts, on the basis of works of famous Indologists, modern European philosophers, an attempt was made to describe the rationality of yoga and give it a definition. The author goes to the general nature of the rationality of the East, represented by a cosmological-mythological worldview. He concludes that for a man of the East there are other norms and criteria of rationality than for a European-oriented worldview. The author also analyzes the nature of the design thinking of a person with this form of worldview.

For a person of the East, there are other norms and criteria for rationality than for a European-oriented worldview. The rationality of the philosophy of yoga should be the basis for research practices and technologies of yoga. It can be given a conditional definition, but its meaning is deep and rooted in hoary antiquity, and requires careful and thorough analysis. The union of all ascetic practices and religious teachings takes place in the Gita, so without analyzing its texts, it is impossible to understand the rationality of yoga. Yoga rationality is mythological and cosmological in nature: it is an a priori scheme of man's perception of the world and himself, in which ideas about karma and nirvana were central to world orientation and activity, and the mystic of cosmic and biological emphasized the polyvalence of these apriorisms. Such rationality allows the yogi to mentally move from the world of carnal beings into the world of gods and into the world of transcendental gods. The last world appears as an intermediate between the phenomenal world and the non-world of nirvana.

Various Indian practices, techniques, and methods aimed at freeing the spirit through separation acquired their followers, because after the "Upanishads" the rejection of life due to socio-political structures and history became the most worthy soteriological solution.

Hence the orientation of the yogi to internal self-improvement and indifference to the outside world. Moral decency and cosmic order here are concepts of the same level, starting with the moral positions of the individual soul, which is akin to the spiritual essence of the Cosmos, and Good and Evil act as metaphors for the rhythmic nature of life, both of Cosmos and of Man. 